\title{
A numerical study of flood effect of a bridge at tail of Ganjiang River, entrance of Poyang Lake
}

\author{
Hua $\mathrm{Ge}^{1, *}$, Chunyan Deng ${ }^{1}$ \\ ${ }^{1}$ Changjiang River Scientific Research Institute, Wuhan, Hubei, 430010, China
}

\begin{abstract}
The construction of a river-crossing bridge will have an impact on the flow movement of the river section, which will bring adverse impact on flood control. In this paper, the influence of a planned bridge project on flood water level and flow field was analysed by using a two-dimensional mathematical model. The calculation results show that the construction of the bridge will cause backwater to the upstream of the bridge, resulting in the elevation of flood water level, thus bringing pressure to the use of flood control dam. At the same time, due to the squeezing effect of bridge piers on the flow, the flow velocity between piers and between piers and embankments on both sides will increase, which will bring adverse effects on the safe operation of the levee and pier.
\end{abstract}

\section{Introduction}

When a bridge crosses a river, piers are usually arranged in the river channel, which will cause the water level of the reach to rise and the local velocity will increase [1-4]. This will affect the flood control of the river reach where the bridge is located. Nanchang City, the capital of Jiangxi Province, is located at the end of Ganjiang River, who flows into China's largest freshwater lake - Poyang Lake. With the economic and social development of Nanchang City, the demand for river-crossing travel is more and more strong, and the bridge is the first choice of river-crossing style. Therefore, the adverse effects of bridge construction on urban flood control must be considered. In this paper, the two-dimensional flow mathematical model was used to calculate and analyse the impact a river-crossing bridge on the flood control in the south of Nanchang City. The results can not only provide the optimization basis for the construction of the bridge in the province, but also provide a reference for the urban flood control in Nanchang City.

\section{Study area, method and data}

\subsection{Study area}

Considering the actual construction location of the proposed bridge, Nanchang river section where the bridge is located was selected as the research area, shown as Figure 1. The study area is located in the main urban area of Nanchang City, of which the left bank is the embankment along the river, and the flood control standard of the dike is 100 year return period flood. The right bank is the East Jiangxi Dykes. After construction in recent years, the flood control standard of the main urban area reaches is the once-in-100-year period, and the flood control standard of the non-main urban area is once every 50 years.

There is Waizhou hydrological station in the study river reach. The hydrological measurement items include water level, discharge, sediment concentration, etc. the observation date started in 1950. Its observation data can provide very detailed water and sediment characteristic values for the study river reach.

\subsection{Method}

In this study, a planed two-dimensional flow mathematical model [5] was used to calculate the impact of a proposed bridge on the flood control. The length of the study river reach is about $30 \mathrm{~km}$ with a width of about $1 \mathrm{~km}$ to $2.5 \mathrm{~km}$. In order to better adapt to the river boundary, the calculation river area was divided by an orthogonal curvilinear grid system [6]. The number of the grid nodes along the flow direction and vertical to flow direction are 408 and 301, respectively. The average scale of the grids is $75 \mathrm{~m}$ along the flow direction, $60 \mathrm{~m}$ in the vertical direction, and the minimum grid size is $5 \mathrm{~m}$ (shown as Figure 2). In order to fully simulate the impact of the proposed bridge project, the grid was encrypted in the local area of the proposed bridge project. The calculation content includes the water level and vertical-averaged velocity of all the grid nodes before and after the construction of the bridge project under different flood frequencies conditions. According to the calculation results, the maximum and minimum changes of water level and velocity, before and after the bridge project, as well as the influence range were counted, and the contour maps of the changes value of water level and velocity before and after the project were drawn.

\footnotetext{
$\overline{{ }^{*} \text { Corresponding author: gh-102@126.com }}$
} 


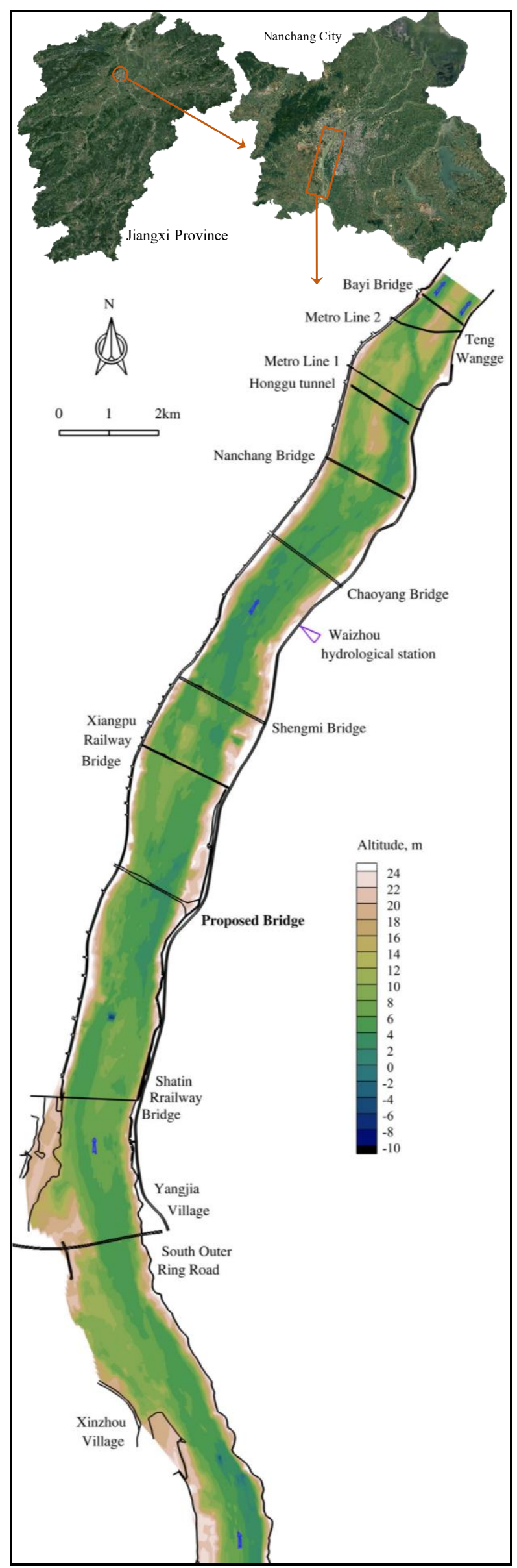

Fig. 1. Map of the study river reach.

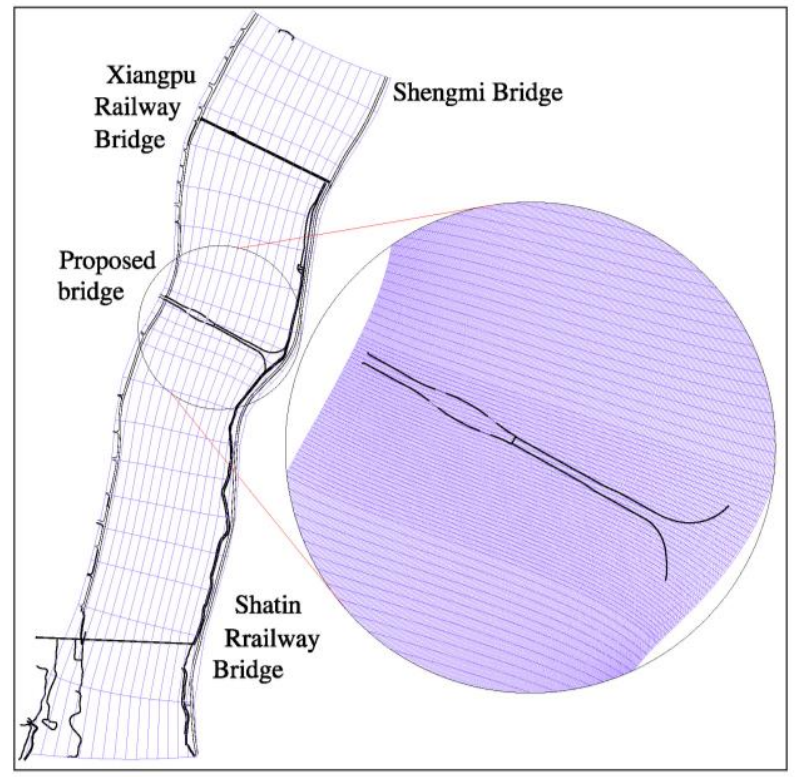

Fig. 2. Map of the orthogonal curvilinear grid system.

\subsection{Data}

The data needed for calculation includes the river bed topography and hydraulic data, such as the water level and discharge of different frequency floods. The terrain data used in this calculation were measured in August 2020, including both the underwater terrain and the land terrain elevation. The model boundary was determined by the frequency calculation and analysis results based on the measured hydrological data of Waizhou hydrological station, the control hydrological station of the study river reach. The Waizhou hydrological station has the discharge data from 1950 to 2019. The maximum daily-averaged flow discharge per year from 1950 to 2019 was shown in Figure 3.

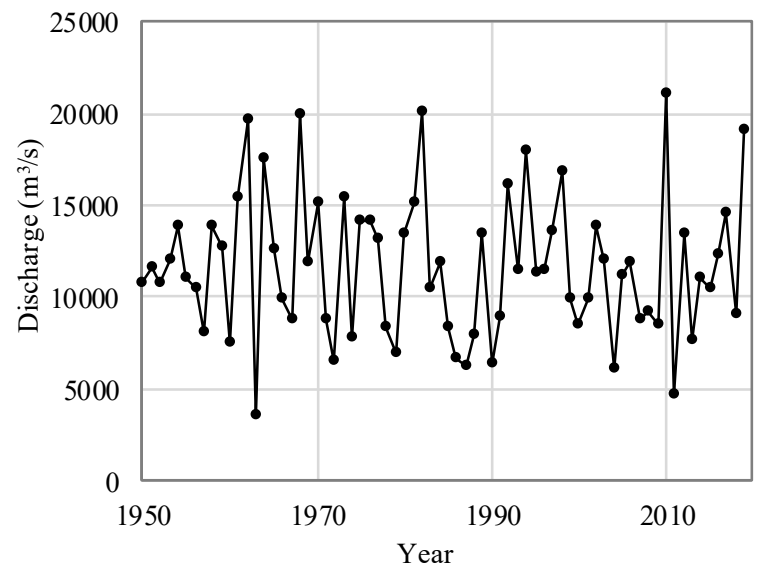

Fig. 3. Map of the maximum daily-averaged flow discharge per year from 1950 to 2019.

The frequency analysis and calculation of flood discharge are based on the measured data and the discontinuous series composed of historical floods investigated in 1901, 1924, 1937 and 1949. According to the relevant results of flood investigation data of Jiangxi Province [7], the historical flood years surveyed by 
Waizhou hydrological station are $1901\left(20800 \mathrm{~m}^{3} / \mathrm{s}\right)$, $1924\left(24700 \mathrm{~m} \mathrm{~m}^{3} / \mathrm{s}\right), 1937\left(1930 \mathrm{~m}^{3} / \mathrm{s}\right)$ and $1949(18000$ $\left.\mathrm{m}^{3} / \mathrm{s}\right)$, and the discharge of 1962,1964 and 1968 were recalculated by the assuming of no dam break at tail Ganjiang River. The discharge after re-calculation is $23600 \mathrm{~m}^{3} / \mathrm{s} 20650 \mathrm{~m}^{3} / \mathrm{s}$ and $21500 \mathrm{~m} \mathrm{~m}^{3} / \mathrm{s}$, respectively. The flood in 1924 is the biggest flood since 1901 . According to this, the return period is 114 years. Among them, the floods in 1962, 1964, 1968, 1982 and 2010 were extracted from the measured series for parameter statistics. The statistical parameters and frequency calculation results of Waizhou hydrological station were obtained by using the P-III frequency curve fitting method [8]. The results are shown in Table 1. And the frequency curve is shown in Figure 4.
Table 1. Frequency discharge calculation results of Waizhou hydrological station.

\begin{tabular}{|c|c|c|c|c|c|c|}
\hline \multirow{2}{*}{$\begin{array}{l}\text { Mean } \\
\text { Value } \\
\left(\mathrm{m}^{3} / \mathrm{s}\right)\end{array}$} & \multirow{2}{*}{$\mathrm{Cv}$} & $\mathrm{Cs} / \mathrm{Cv}$ & \multicolumn{4}{|c|}{ Frequency discharge $\left(\mathrm{m}^{3} / \mathrm{s}\right)$} \\
\cline { 4 - 7 } & & & $1 \%$ & $2 \%$ & $5 \%$ & $10 \%$ \\
\hline 12500 & 0.36 & 2.5 & 25500 & 23450 & 20530 & 18210 \\
\hline
\end{tabular}

According to the flood control standard of the study river reach, the 100 year return period and 50 year return period flood were selected as the model boundary conditions.

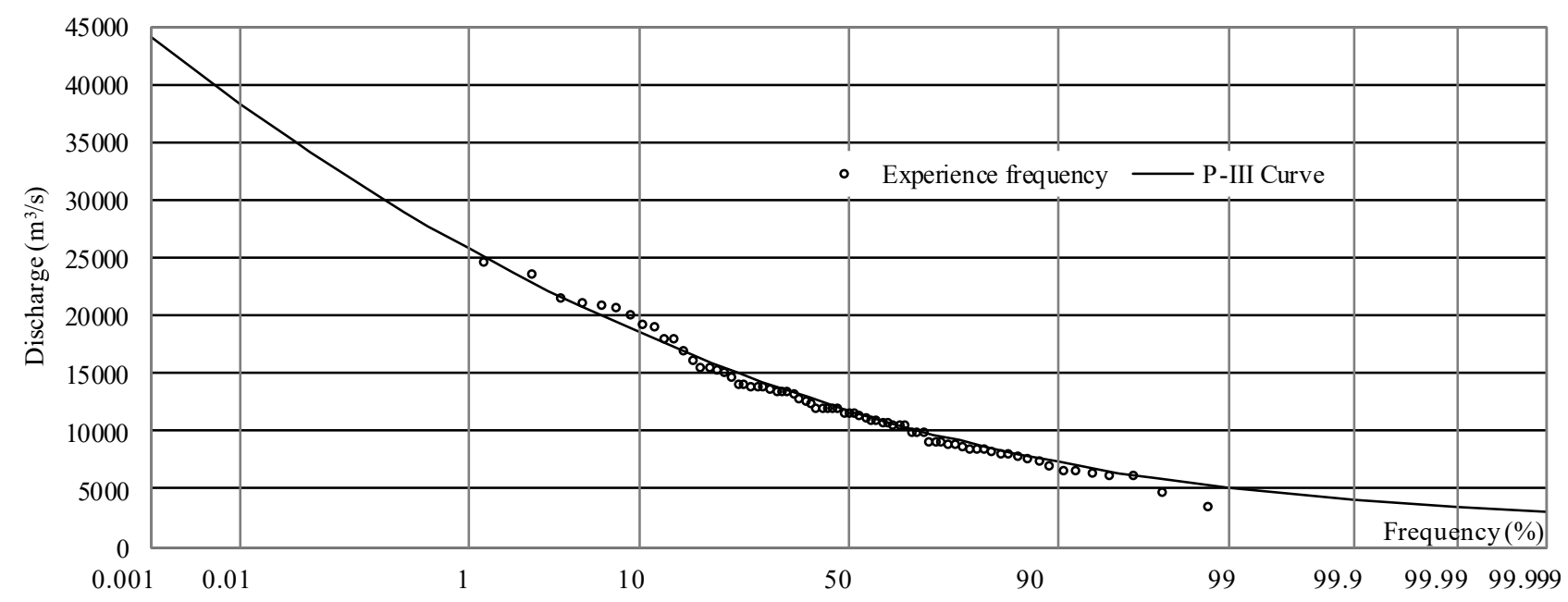

Fig. 4. Map of hydrological frequency analysis results.

\section{Results}

\subsection{Influence on the water level}

Figure 5 is the contour map of the water level change value near the proposed bridge project in the study river reach, and Table 2 is the statistics of the maximum and minimum water level change after the building of the bridge project. It can be seen from the Figure 4 and Table 2 that the water level changes after the project are mainly concentrated in the local areas upstream and downstream of the piers.

Table 2. Statistics of maximum and minimum water level change after the proposed bridge project.

\begin{tabular}{|c|c|c|c|}
\hline \multirow{2}{*}{ Items } & \multicolumn{2}{|c|}{ Changes $(\mathrm{cm})$} & \multirow{2}{*}{ Backwater area } \\
\cline { 2 - 3 } & Increase & Decrease & \\
\hline $\mathrm{P}=1 \%$ & 5.4 & -5.5 & $1400 \mathrm{~m}$ upstream \\
\hline $\mathrm{P}=2 \%$ & 4.8 & -4.9 & $1300 \mathrm{~m}$ upstream \\
\hline
\end{tabular}

Under the condition of $1 \%$ frequency flood, the maximum backwater level is $5.4 \mathrm{~cm}$ and the minimum drawdown is $5.5 \mathrm{~cm}$. The range of backwater area is limited to $1400 \mathrm{~m}$ upstream of the project.

Under the condition of $2 \%$ frequency flood, the variation range of water level is relatively small. The maximum backup height of water level is $4.8 \mathrm{~cm}$, and the minimum value of water level decrease is $4.9 \mathrm{~cm}$. The range of water level backup is limited to $1300 \mathrm{~m}$ upstream of the project.

\subsection{Influence on the flow velocity}

Figure 6 shows the contour map of velocity changes after the bridge construction, and Table 3 shows the maximum value of velocity changes. It can be seen from the Figure 5 and Table 3 that: the proposed bridge has a little impact on the overall flow field of the study river section, and the change of the flow velocity after the implementation of the bridge project is mainly located in the local areas, upstream and downstream of the proposed bridge.

Under the condition of $1 \%$ frequency flood, the maximum value of velocity increase is $0.35 \mathrm{~m} / \mathrm{s}$, and the area of velocity increase is mainly between the piers of the bridge; the maximum value of velocity decrease is $1.2 \mathrm{~m} / \mathrm{s}$, the area of velocity decrease is upstream and downstream of bridge piers. The influence range of velocity is limited from $1400 \mathrm{~m}$ upstream to $4300 \mathrm{~m}$ downstream of bridge. 
Under the condition of $2 \%$ frequency flood, the change trend and rule of velocity are the same as those under $1 \%$ frequency flood, but the change value and influence range of velocity are reduced. The maximum value of velocity increase is $0.31 \mathrm{~m} / \mathrm{s}$, and the maximum decrease value is $1.1 \mathrm{~m} / \mathrm{s}$. The influence range of velocity is limited in the range of $1200 \mathrm{~m}$ upstream to $3900 \mathrm{~m}$ downstream of the bridge.
Table 3. Statistics of maximum and minimum velocity change after the project.

\begin{tabular}{|c|c|c|c|}
\hline \multirow{2}{*}{$\begin{array}{c}\text { Items } \\
\text { Frequency }\end{array}$} & \multicolumn{2}{|c|}{ Changes $(\mathrm{m} / \mathrm{s})$} & \multirow{2}{*}{ Increase } \\
\cline { 2 - 3 } Decrease & \\
\hline $\mathrm{P}=1 \%$ & 0.35 & -1.2 & Up $1.4 \mathrm{~km}$ to down $4.3 \mathrm{~km}$ \\
\hline $\mathrm{P}=2 \%$ & 4.8 & -4.9 & $\mathrm{Up} 1.2 \mathrm{~km}$ to down $3.9 \mathrm{~km}$ \\
\hline
\end{tabular}

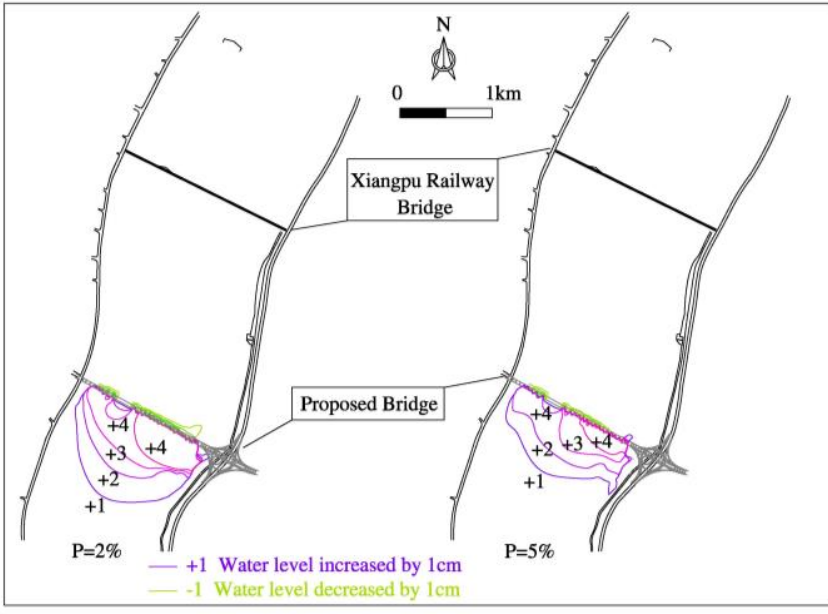

Fig. 5. Contour map of water level change.

\section{Conclusions}

The calculation results of two-dimensional mathematical model show that after the proposed bridge project is implemented, a little impact on the flow is brought, and the impact is mainly reflected as a raised water level in the upstream area of the proposed bridge, and the water level in the local area downstream of the piers is decreased. Due to the squeezing effect of piers, the flow velocity between piers increases, and the flow velocity in the upstream and downstream area of piers are decreased by the water blocking effect of piers. From the calculation results of different flood frequencies, it can be seen that the greater the discharge, the greater the impact of bridge on water flow. The above results show that the construction of a bridge will increase the local flood control pressure of the river, but the impact is limited to the upstream and downstream of the bridge.

\section{Acknowledgments}

This work was supported by National Key R\&D Program of China 2017YFC0405306, and the Second Stage Research Project of Key Technologies for Scientific Operation of the Three Gorges Reservoir (0714167).

\section{References}

1. WU Shiqiang, XUE Wanyun, WU Xiufeng, etc. Study on Quantitative Water-Blocking

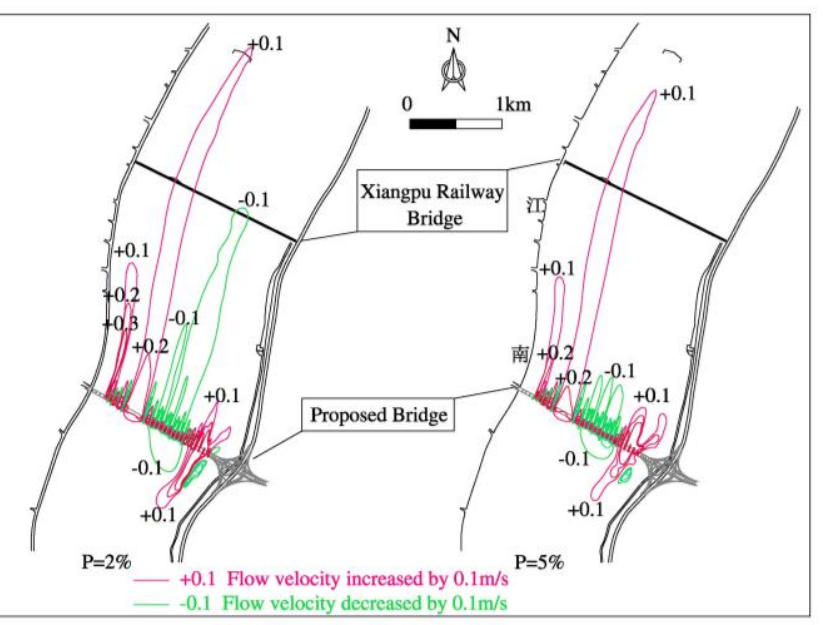

Fig. 6. Contour map of flow velocity change.

Superposition Effect of Bridge Group on Urban Flood Channel. YELLOW RIVER, 41, 10 (2019)

2. ZHAO Zhongwei, MA Liang, YUAN Shuai. Flood Control Analysis for Skew Bridge Crossing Mountain Channel Based on Two-Dimensional Numerical Model. YELLOW RIVER, 41, 4 (2019)

3. LIANG Zhaoyun. Study on the Range of Flood Defense Influence Evaluation and Calculation of Bridge across the Floodplain River. GUANGDONG WATER RESOURCES AND HYDROPOWER, 3, (2019)

4. LI Bin. A Comprehensive Discriminant Index of Water-blocking Influence from Bridge to River. Journal of North China University of Water Resources and Electric Power ( Natural Science Edition), 38, 2 (2017)

5. Ge, Hua. Modeling of Fluvial Processes for Braided Channel in Down Yangtze River, Part 1: Model Building and Validation. Earth and Environmental Science, 304, 2 (2019)

6. HE Guo-jian, WANG De-guan, LIU Xiao-bo. Numerical procedure for generation of 2-D orthogonal body-fitted curvilinear coordinate system with arbitrarily determined grid points on the boundary. Journal of Hohai University (Natural Sciences), 32, 2 (2004)

7. Luo Chengzheng. Historical flood in China. China Bookstore press, Beijing : 2006

8. Zhao Xiaoshen, Wang Weidong. Optimal wiring and automatic drawing of Pearson - III distribution curve. YELLOW RIVER, 29, 4 (2007) 